\title{
BMJ Open Knowledge and practice of prostate cancer screening among general practitioners in Malaysia: a cross-sectional study
}

\author{
Abdul Malik Tun Firzara, Chirk Jenn Ng
}

To cite: Tun Firzara AM, $\mathrm{Ng}$ CJ. Knowledge and practice of prostate cancer screening among general practitioners in Malaysia: a cross-sectional study. BMJ Open 2016;6:e011467. doi:10.1136/bmjopen-2016011467

- Prepublication history and additional material is available. To view please visit the journal (http://dx.doi.org/ 10.1136/bmjopen-2016011467).

Received 15 February 2016 Revised 11 August 2016 Accepted 16 August 2016

CrossMark

Faculty of Medicine, Department of Primary Care Medicine, University of Malaya, Kuala Lumpur, Malaysia

Correspondence to Dr Tun Firzara Abdul Malik; tunfirzara@um.edu.my

\begin{abstract}
Objective: Screening for prostate cancer remains controversial. General practitioners (GPs) play an important role in assisting men to make an informed decision on prostate cancer screening. The aim of this study was to determine the knowledge and practice of prostate cancer screening among private GPs in Malaysia.

Design: A cross-sectional study.

Setting: Private general practices in Selangor, Malaysia.
\end{abstract}

Participants: 311 randomly selected full-time private GPs were recruited between September 2013 and January 2014.

Outcome measures: Questionnaires were distributed to the GPs via postal mail and clinic visits. The main outcomes were: knowledge of prostate cancer risk factors and screening tests; GPs' prostate cancer screening practices; and factors influencing GPs' decision to screen for prostate cancer. Associations between covariates and propensity to screen for prostate cancer were determined using logistic regression.

Results: The response rate was $65 \%$. The proportion of GPs who overestimated the positive predictive values of prostrate-specific antigen (PSA), digital rectal examination (DRE) and a combination of PSA and DRE was $63 \%, 57 \%$ and $64 \%$, respectively. About $49.5 \%$ of the respondents would routinely screen asymptomatic men for prostate cancer; of them, $94.9 \%$ would use PSA to screen. Male GPs who would consider having a PSA test performed on themselves were six times more likely to screen asymptomatic men than GPs who would not have the test $(\mathrm{OR}=6.88,95 \% \mathrm{Cl} 1.40$ to 33.73), after adjusting for age and duration of practice. Conclusions: GPs overestimated the accuracy of PSA in prostate cancer screening. Their intention to screen for prostate cancer themselves predicted their propensity to screen their patients for prostate cancer. This finding highlights the potential of using a new approach to change GPs' screening practices via addressing GPs' own screening behaviour.

\section{INTRODUCTION}

Evidence on prostate cancer screening has been contradictory. The results from two

\section{Strengths and limitations of this study}

- The participants were selected randomly.

- Although the response rate was $<70 \%$, this is considered reasonable for surveys targeting physicians which is generally lower.

- The findings from this study may not be generalisable to general practitioners (GPS) in the public sector and rural setting.

- There is a possibility that GPs may not report their actual screening practices as the information was self-reported.

major randomised trials in Europe and the USA were conflicting: the European Randomised Study of Screening for Prostate cancer (ERSPC) ${ }^{1}{ }^{2}$ showed a reduction in mortality while the Prostate, Lung, Colorectal, Ovarian Cancer (PLCO) trial did not find a reduction in mortality. ${ }^{3}{ }^{4}$ Recommendations from clinical practice guidelines have also been inconsistent. The European Association of Urology (EAU) and the National Comprehensive Cancer Network (NCCN) recommend screening for prostate cancer, ${ }^{5}{ }^{6}$ while the US Preventive Service Task Force $(\text { USPSTF })^{7}$ is against it. Other organisations which include the American Urological Association (AUA), ${ }^{8}$ American College of Physicians (ACP) ${ }^{9}$ and American Cancer Society (ACS) ${ }^{10}$ recommend that doctors should involve men in shared decision-making when discussing prostate cancer screening.

The root of the controversy is whether prostrate-specific antigen (PSA) testing as a screening tool for prostate cancer confers net benefit. Relatively low prostate cancer sensitivity of $20.5 \%$ was reported for PSA cut-off values of $4.0 \mathrm{ng} / \mathrm{mL}$; however, the sensitivity of PSA for aggressive prostate cancer (Gleason grade 8 or higher) was greater at $51 \% .^{11}$ PSA testing has a high false-positive rate of $80 \%$ with low positive predictive 
value. ${ }^{7}$ Prostate biopsy, as a result of a positive screening result, may cause anxiety, physical discomfort, bleeding and infection ${ }^{12}$ while prostate cancer treatment may result in sexual dysfunction, urinary incontinence and bowel problems. ${ }^{13}$ Overdiagnosis is also another potential harm as life expectancy may remain unchanged in most men with prostate cancer as it is a slow-growing tumour. $^{7}$

Despite this, prostate cancer screening is common, particularly in the primary care setting, where preventive care is encouraged. In Canada, Ireland and New Zealand, more than half of the GPs screen their male patients for prostate cancer ${ }^{14-16}$ and a majority of them overestimated the performance of prostate cancer screening tools. ${ }^{15}{ }^{16}$ Factors that have been found to influence GPs' prostate cancer screening practice are: patients' age, ${ }^{15-17}$ family history ${ }^{17-19}$ and patients' request $;{ }^{17-19}$ doctors' age, ${ }^{15}{ }^{20}$ gender ${ }^{15}$ duration of practice $^{15}$ and influence from guidelines and trials; ${ }^{17}$ and whether the practice runs well man clinics and performs occupational health checks and other tests routinely with PSA. $^{15}$

Several risk factors have been associated with prostate cancer, including increased age and family history of prostate cancer. ${ }^{21}$ Family history of a first-degree relative with breast cancer was also found to increase a man's risk of prostate cancer, ${ }^{22}$ especially carriers of BRCA2 mutations. ${ }^{23}$ There were also several studies which have looked into other factors such as smoking, dietary intake and benign prostate hyperplasia but the results were not significant. ${ }^{24-27}$

In Malaysia, prostate cancer is the fourth most common cancer among men. ${ }^{28}$ Its incidence is rising due to the ageing population and possibly an increase in the prostate cancer screening rate. However, so far, there is no consensus on prostate cancer screening in the population and there is no clinical practice guideline to guide GPs on whether or not to screen for prostate cancer. There are also no data on the PSA testing rate in Malaysia. Hence, it remains unknown whether GPs in Malaysia, in the absence of proper guidance, are screening for prostate cancer and, if so, whether they are aware of the pros and cons of prostate cancer screening. Therefore, the aim of this study was to determine the knowledge and practice of prostate cancer screening among private GPs in Malaysia.

\section{METHODS}

We conducted a cross-sectional study in private GP clinics in Petaling District, which is an urban area located in the state of Selangor, Malaysia, adjacent to the capital of Kuala Lumpur. The healthcare system in Malaysia is divided into public and private sectors. Patients pay a standard minimal fee for the public healthcare system, whereas the private sector charges patients based on the services provided. We conducted the study in private GP clinics as the PSA test is readily available while in the public primary care clinics, the test is not available and it is not part of the policy to screen for prostate cancer.

The inclusion criteria were full-time private GPs who managed adult male patients. The sampling frame consisted of all private GP clinics in Petaling District which has a total of 683 clinics. All GP clinics are registered with the Private Medical Practice Control Unit. In practices with more than one GP, only one GP was chosen by the practice to participate. The sample size was calculated using Stata V.11.0. By using 50\% as the predicted screening rate with a margin of error of $10 \%, \alpha$ of 0.05 and power of $80 \%$, the estimated sample size was 194 . Considering a response rate of $60 \%$, the final sample size was 311 . Simple random sampling was used to select the practices via computer-generated numbers.

A self-administered questionnaire was adapted from a previous survey developed by Drummond et $a l^{15}$ from the National Cancer Registry Ireland. The questionnaire consisted of 34 items with sections on: (1) GPs' sociodemographic profile; (2) practice profile; (3) knowledge of prostate cancer risk factors and screening tests; (4) prostate cancer screening practice; and (5) management of PSA results and information needs (see online supplementary appendix 1). Positive predictive value was defined as the likelihood that a positive result indicates prostate cancer. We performed content and face validation of the questionnaire among eight healthcare professionals who have expertise in prostate cancer screening including urologists, family medicine specialists and GPs. The questionnaire was modified based on the feedback from the expert panel. A pilot study was conducted to look at the feasibility and acceptability of the study. Ten GPs participated in the pilot study.

Data collection was carried out from September 2013 to January 2014. Questionnaires, participant information sheet and consent form were posted to 311 randomly selected general practices. The questionnaire was assigned a numerical code to ensure confidentiality. A reminder letter was sent 2 weeks later. Owing to the poor response rate from the postal survey $(9.6 \%)$, the researcher visited the remaining GPs personally to improve the response rate. The researcher followed the code of ethics when approaching the GPs at their clinics. The participants were allowed to answer the questions privately and the researcher avoided influencing them in any way.

\section{Statistical analysis}

We used the Statistical Package for Social Sciences (SPSS) V.21.0 to manage and analyse the data. There were no missing data because the participants were contacted to complete the missing data in the questionnaires. Percentages were used to summarise categorical data. Mean and SD were used to describe continuous variables which were normally distributed while median was used for those which were skewed. We used Pearson's $\chi^{2}$ test to test for univariate associations 
between categorical variables. We used the item 'Do you usually screen asymptomatic men for prostate cancer' as the dependent variable. Multivariate logistic regression analysis was performed to identify independent factors which influenced GPs' decision to screen for prostate cancer. Only factors that were found to be statistically significant $(\mathrm{p}<0.05)$ in univariate analyses were included in the multivariable model. When we analysed the level of knowledge of positive predictive value (PPV) for prostate cancer screening, overestimation was considered incorrect. We considered the correct estimation of PPV for PSA alone and DRE alone as $<30 \%$ while PPV for combination of both as $<50 \% .{ }^{1529} 30$ Several continuous variables were grouped into categories: (1) age of GP $(<40,40-60$ and $>60)$ and (2) length of practice $(\leq 10$, $11-20,21-30,>30)$. These categories are based on stages of the GP career. We hypothesise that at different stages of the GPs' career, their practice of prostate screening might change. Female participants were excluded from the multivariable model for the item 'Would you consider having a PSA test performed yourself in the future?' because the question was not relevant to them and hence was not asked.

\section{RESULTS}

\section{Response rate and sociodemographic profile of}

\section{participants}

We distributed questionnaires by mail to 311 clinics. Only 30 GPs $(9.6 \%)$ returned the questionnaires by post. Subsequently, we visited the remaining 281 GP clinics. Nine GPs were excluded from the study (five were not full-time GPs and four did not see adult male patients). A total of 196 GPs agreed to participate in the study (30 by mail, 166 from clinic visits), giving a response rate of $65 \%(196 / 302)$. The targeted sample size of 194 was achieved. Table 1 shows the GPs' and practice profile. Reasons for non-participation were lack of time and they were not interested in the research.

\section{GPs' knowledge on prostate cancer risk factors and screening tests}

A majority of the respondents correctly answered the questions on 'increased age of over 50 years' (97.4\%) and 'having a first-degree relative with prostate cancer' $(82.7 \%)$ increase the risk of prostate cancer. Fewer of them $(31.1 \%)$ were aware that having a first-degree relative with breast cancer increases the risk of prostate cancer (table 2). The proportion of GPs who overestimated the PPV of PSA, DRE and both combined were $63.3 \%, 56.6 \%$ and $64.3 \%$, respectively. The results are summarised in table 3 .

\section{GPs' practice of prostate cancer screening}

Almost half of the respondents $(49.5 \%)$ reported that they would usually screen asymptomatic men for prostate cancer. There is no significant difference in screening rates between those who responded by mail and those

\begin{tabular}{|c|c|}
\hline Characteristics of respondents & $\begin{array}{l}N(\%) / \text { mean/ } \\
\text { median } \\
(n=196)\end{array}$ \\
\hline \multicolumn{2}{|l|}{ Gender } \\
\hline Male & $128(65.3 \%)$ \\
\hline \multicolumn{2}{|l|}{ Age } \\
\hline Mean age $\pm S D$ (years) (range) & $48.3 \pm 11.4(26-83)$ \\
\hline \multicolumn{2}{|l|}{ Length of practice } \\
\hline Mean age $\pm S D$ (years) (range) & $15.8 \pm 10.7(0.5-53)$ \\
\hline Median (years) & 15 \\
\hline $\begin{array}{l}\text { GPs with postgraduate } \\
\text { qualifications }\end{array}$ & $53(27.0 \%)$ \\
\hline \multicolumn{2}{|l|}{ Number of GPs in practice } \\
\hline Mean $\pm S D$ (range) & $3.0 \pm 2.8(1-16)$ \\
\hline Median & 2 \\
\hline \multicolumn{2}{|l|}{ Number of patients in a day } \\
\hline Mean $\pm S D$ (range) & $36.01 \pm 18.2(4-90)$ \\
\hline Median & 30 \\
\hline
\end{tabular}

who responded after visiting their clinics $(56.7 \%$ vs $48.2 \%, p=0.39)$. Nearly all GPs $(94.9 \%)$ would use PSA if they intended to screen for prostate cancer. At least half of the GPs $(51.5 \%)$ believed that healthy men aged 50 years and above should be tested for PSA annually or less while $22.4 \%$ believed that a PSA test should be performed only when a man with risk factors develops lower urinary tract symptoms. A majority $(76 \%)$ of the GPs reported that they frequently informed the patient that his PSA was being checked as part of the screening package. About $61.2 \%$ of the GPs would frequently discuss the implication of an abnormal proposed PSA test. Only $20.4 \%$ of them would frequently discuss the treatments of prostate cancer in general terms before performing a PSA test. A majority of the male GPs $(89.8 \%)$ would consider undergoing a PSA test themselves.

\section{Factors associated with the propensity of GPs to screen asymptomatic men for prostate cancer}

From univariate analyses, we found three factors to be significantly associated with GPs' propensity to screen for prostate cancer (1) older age group $(\mathrm{p}=0.02)$ with unadjusted OR 2.04 (95\% CI 1.01 to 4.13) for age group $40-60$ and 3.55 (95\% CI 1.41 to 8.97 ) for age group above 60 ; (2) longer duration of practice $(\mathrm{p}=0.03)$ with unadjusted OR of 2.15 (95\% CI 1.11 to 4.16) for 11-20 years of practice and 3.11 (95\% CI 1.28 to 7.56$)$ for 21-30 years of practice; and (3) GPs who considered having a PSA test performed on themselves $(\mathrm{p}=0.01)$ with unadjusted OR of 7.30 (95\% CI 1.55 to 34.43 ; table 4).

By using the logistic regression model, GPs who would have a PSA test themselves was the only independent predictor of GPs' propensity to screen for prostate cancer with OR 6.88 (95\% CI 1.40 to 33.73 ; table 4 ). 
Table 2 GPs' knowledge of prostate cancer risk factors

\begin{tabular}{|c|c|c|}
\hline $\begin{array}{l}\text { Knowledge of risk factors } \\
\text { 'For each of the following, please indicate whether you } \\
\text { believe they influence the risk of developing prostate cancer' }\end{array}$ & Number who answered correctly $(n=196)$ & Per cent \\
\hline Increased age (over 50 years) (increases risk) & 191 & 97.4 \\
\hline 1st degree relative with prostate cancer (increases risk) & 162 & 82.7 \\
\hline 1st degree relative with breast cancer (increases risk) & 61 & 31.1 \\
\hline Benign prostatic hyperplasia (does not affect risk) & 43 & 21.9 \\
\hline Current smoking (does not affect risk) & 36 & 18.4 \\
\hline High dietary fat intake (does not affect risk) & 35 & 17.9 \\
\hline
\end{tabular}

\section{DISCUSSION}

There are three main findings in this study. First, more than half of the GPs overestimated the PPV of prostate cancer screening tools. Second, almost half of the GPs $(49.5 \%)$ would screen asymptomatic med for prostate cancer and a majority (94.9\%) would use PSA if they intended to screen; this is despite the unavailability of national guideline and the controversies with regard to prostate cancer screening. Finally, GPs who would consider having a PSA test performed on themselves were six times more likely to screen asymptomatic men than GPs who would not have the test.

A majority of the respondents correctly identified firstdegree family history of prostate cancer $(82.7 \%)$ and increased age of more than 50 years (97.4\%) as risk factors for prostate cancer. However, more than half of the respondents $(68.9 \%)$ were unaware of family history of breast cancer in a first-degree relative as a risk factor for prostate cancer. These findings are similar to the previous study carried out in Ireland and the USA. ${ }^{15} 17$ This could be due to the perception that prostate cancer is a male disease and hence doctors may not link it to breast cancer.

Our study also revealed that there was poor knowledge on the performance of prostate cancer screening tools.

\begin{tabular}{|c|c|c|}
\hline Knowledge of PPV & Number $(n=196)$ & Per cent \\
\hline \multicolumn{3}{|l|}{ PPV of PSA } \\
\hline Correct estimation $<30 \%$ & 54 & 27.6 \\
\hline Overestimate $>30 \%$ & 124 & 63.3 \\
\hline Not sure & 18 & 9.2 \\
\hline \multicolumn{3}{|l|}{ PPV of DRE } \\
\hline Correct estimation $<30 \%$ & 50 & 25.5 \\
\hline Overestimate $>30 \%$ & 111 & 56.6 \\
\hline Not sure & 35 & 17.9 \\
\hline \multicolumn{3}{|l|}{ PPV of PSA and DRE } \\
\hline Correct estimation $<50 \%$ & 47 & 24.0 \\
\hline Overestimate $>50 \%$ & 126 & 64.3 \\
\hline Not sure & 23 & 11.7 \\
\hline
\end{tabular}

More than half of the GPs believed that the PPV of PSA (alone), DRE (alone) and a combination of PSA and DRE were higher than the values reported in the literature. ${ }^{29-33}$ This finding is also similar to the study carried out in Ireland where $54 \%$ of the GPs overestimated the likelihood that a positive PSA result indicated prostate cancer and $68 \%$ overestimated the PPV of PSA and DRE. ${ }^{15}$ Another study carried out in New Zealand also reported that a majority of GPs overestimated the PPV for DRE and more than one-third overestimated the PPV of the PSA. ${ }^{14}$ This could be due to a lack of update or awareness among GPs on prostate cancer screening methods. Further study needs to be carried out to find out the reasons regarding the gaps of knowledge among the GPs. This is important as overestimation implies that GPs might screen excessively and might not have given men accurate information about the screening test.

There was a variation in GPs' practice in prostate cancer screening. In this study, about half of the GPs $(49.5 \%)$ screened asymptomatic men for prostate cancer; this is lower than the study carried out in Canada and the UK, where $87 \%$ and $76 \%$ of the GPs would screen asymptomatic men for prostate cancer, respectively. ${ }^{16}$ The high screening rate in Canada was found to be related to the fee-for-service scheme and high-volume practice. ${ }^{11}$ The GPs' screening behaviour in Canada and the UK are also influenced by having a local guideline which recommended GPs to offer prostate cancer screening readily followed by discussing the risks and benefits with the patients. ${ }^{18} 34$ In this study, GPs were almost evenly divided between those who screened and those who did not, which is probably due to the fact that local guidelines are not available and thus screening might be based on individual beliefs and preferences as well as taking into account the cost that patients need to pay for the test. It could also be due to the PSA test being part of a screening package available in the GP clinics.

However, this study found that most $(94.9 \%)$ of the respondents would use PSA if they intended to screen for prostate cancer. This finding paralleled that of an Irish study where more than three-quarters of the GPs reported that they would usually use PSA to screen for prostate cancer. ${ }^{15}$ However, this study was conducted 
Table 4 Logistic regression analysis: factors associated with the propensity of GPs to screen asymptomatic men for prostate cancer

\begin{tabular}{|c|c|c|c|c|c|}
\hline Factors & Propensity to screen N (\%) & Unadjusted OR (95\% Cl) & p Value & Adjusted OR (95\% Cl) & $\overline{p \text { Value }}$ \\
\hline \multicolumn{6}{|l|}{ GP characteristics } \\
\hline \multicolumn{6}{|l|}{ Age group } \\
\hline$<40$ & $16 / 47(34.0)$ & 1 & & 1 & \\
\hline $40-60$ & $59 / 115(51.3)$ & 2.04 (1.01 to 4.13$)$ & $0.02^{\star *}$ & 1.09 (0.33 to 3.62$)$ & 0.88 \\
\hline$>60$ & $22 / 34(64.7)$ & 3.55 (1.41 to 8.97$)$ & & $1.82(0.32$ to 10.42$)$ & 0.50 \\
\hline \multicolumn{6}{|l|}{ Gender } \\
\hline Male & $64 / 128(50.0)$ & 1.06 (0.59 to 1.91$)$ & 0.85 & & \\
\hline Female & $33 / 68(48.5)$ & 1 & & & \\
\hline \multicolumn{6}{|c|}{ Length of practice (years) } \\
\hline$\leq 10$ & $25 / 70(35.7)$ & 1 & $0.03^{\star *}$ & 1 & 0.11 \\
\hline $11-20$ & $43 / 79$ & $2.15(1.11$ to 4.16$)$ & & 2.44 (0.82 to 7.23$)$ & 0.41 \\
\hline $21-30$ & $19 / 30(63.3)$ & 3.11 (1.28 to 7.56$)$ & & $1.81(0.44$ to 7.47$)$ & 0.68 \\
\hline$>30$ & $10 / 17(58.8)$ & 2.57 (0.87 to 7.59$)$ & & $1.49(0.23$ to 9.54 & \\
\hline \multicolumn{6}{|l|}{ Knowledge } \\
\hline \multicolumn{6}{|l|}{ PPV of PSA } \\
\hline$<30 \%$ (correct) & 29/54 (53.7) & 1 & 0.55 & & \\
\hline Overestimate & $61 / 124(49.2)$ & 0.55 (0.19 to 1.63$)$ & & & \\
\hline Not sure & $7 / 18(38.9)$ & $0.66(0.24$ to 1.81$)$ & & & \\
\hline \multicolumn{6}{|l|}{ PPV of DRE } \\
\hline$<30 \%$ (correct) & $24 / 50(48.0)$ & 1 & 0.61 & & \\
\hline Overestimate & $58 / 111(52.2)$ & $0.81(0.34$ to 1.94$)$ & & & \\
\hline Not sure & $15 / 35(42.8)$ & $0.69(0.32$ to 1.47$)$ & & & \\
\hline \multicolumn{6}{|c|}{ PPV of PSA and DRE } \\
\hline$<50 \%$ (correct) & $25 / 47(53.2)$ & 1 & 0.74 & & \\
\hline Overestimate & $62 / 126(49.2)$ & $0.68(0.25$ to 1.85$)$ & & & \\
\hline Not sure & $10 / 23(43.4)$ & $0.79(0.32$ to 1.94$)$ & & & \\
\hline \multicolumn{6}{|c|}{ Consider having a PSA test yourself* } \\
\hline No & $2 / 13(15.4)$ & 1 & $0.01^{\star *}$ & 1 & $0.017^{\star \star}$ \\
\hline Yes & $65 / 115(56.5)$ & $7.3(1.55$ to 34.43$)$ & & 6.88 (1.40 to 33.73$)$ & \\
\hline
\end{tabular}

before the recent revised recommendation from USPSTF, AUA and ACS which recommend against screening actively for prostate cancer. Nevertheless, the GPs in this study still actively performed PSA testing for their patients, which may be explained by the lack of awareness and familiarity with recent international guidelines. ${ }^{35}$ Another reason could be due to their belief that early detection can improve survival for men with prostate cancer, which was reported by a majority of GPs in Canada and Australia. ${ }^{16} 36$ GPs are also concerned about litigation should the patient later be diagnosed with prostate cancer. ${ }^{36}{ }^{37}$ Media also play a role in encouraging men to actively screen for prostate cancer. ${ }^{14} 38$

In this study, a majority of the GPs believed that they should screen healthy men aged 50 years and above for prostate cancer, at least on an annual basis. This is different from previous studies carried out in Ireland and New Zealand where only about $30 \%$ would test men for PSA every year or more frequently. ${ }^{15}$ Another study by Curran et $a l^{16}$ reported that a majority of the GPs would only screen annually for men aged above 70 years. The 2013 AUA guideline recommends a screening interval of 2 years or more as compared to annual screening to reduce over diagnosis and false-positive results. ${ }^{8}$ This again could be due to the GPs' own beliefs and preferences and absence of local policy to guide them on the screening practice.

Up to a quarter of GPs in this study would not routinely disclose to their patient that his PSA was being checked; in contrast, only $10 \%$ of the GPs from Ireland would do so. ${ }^{15}$ Similarly, in this study, $39 \%$ of GPs would not routinely discuss the implications of an abnormal PSA test and treatments of prostate cancer prior to PSA testing. This is of concern as this would mean that men would not be involved in making decisions whether or not to undergo prostate cancer screening. This is consistent with a situational analysis conducted in Malaysia which found that patients were not provided with adequate information to make an informed decision. ${ }^{39}$ A shared decision-making approach has been recommended by a number of prostate cancer screening guidelines published recently. ${ }^{8-10}$ The reasons for GPs not disclosing and discussing the pros and cons of prostate cancer screening with men could be due to the lack of knowledge or skills in communicating risks to 
patients. ${ }^{40}$ Currently, there is no structured shared decision-making training in Malaysia. Cultural and language diversity may also hinder GPs' communication with their patients about the risks and benefits of prostate cancer. ${ }^{39}$ GPs may also worry that they might lose their patients or patients may become anxious and decide not to take up the test if the risks were informed prior to testing. ${ }^{40}$

This study found that GPs' personal inclination of having a PSA test performed on themselves was a significant independent predictor for them to screen their patients for prostate cancer. This is similar to the previous study conducted by Drummond et $a l^{15}$ where male GPs who would have a PSA test themselves were eighttimes more likely to perform a PSA test for asymptomatic men than GPs who would not have a test. A study carried out by Haggerty et $a t^{11}$ also revealed that the ordering of cancer screening tests was highest among physicians who believed that routine screening was recommended compared to those who think recommendation was unclear or not recommended. GPs' beliefs are usually reinforced by their own and patients' experiences as well as by their interactions with their colleagues, opinion leaders and pharmaceutical representatives. ${ }^{42}$ In Australia, although the guideline recommends against prostate cancer screening, many GPs still would not change their current practice unless the evidence shows that screening for prostate cancer is harmful. ${ }^{36}$

In this study, sociodemographic characteristics of GP and knowledge of PPV of prostate cancer screening methods did not significantly influence GPs' propensity to screen for prostate cancer. A study carried out in the USA also did not find any associations between demographic, practice characteristic or knowledge scores and GPs' prostate cancer screening behaviour. ${ }^{43}$ Knowledge has not been found to be associated with a higher propensity to screen in another study by Tasian et al. ${ }^{37}$ Moran $e t a l^{44}$ reported that a physician's knowledge may not be an important factor that influences the physician's decision to screen for prostate cancer due to the lack of definitive evidence to support the use of PSA. Therefore, this highlights that patient care may be prejudiced by the doctor's own personal view and experience rather than knowledge or evidence.

The strength of this study is that the participants were selected randomly and it has achieved a reasonable response rate of $65 \%$. Although the response rate was $<70 \%$, this is considered reasonable for surveys targeting physicians which is generally lower. ${ }^{45}$ However, the findings from this study could not be generalisable to the public GPs and rural setting. Since we collected selfreported data, there is a possibility that GPs may not report their actual screening practices. Another limitation is the small number of events (propensity to screen) in GPs who did not consider having the PSA test $(n=2 / 13)$. This may affect the validity of the regression model.
The findings from this study highlight a need to convince and educate GPs on the pros and cons of prostate cancer screening as well as the importance of involving men in shared decision-making before ordering PSA tests. A national guideline on prostate cancer screening would be useful to highlight the current controversies and provide guidance for GPs on the practice of prostate cancer screening. Patient decision support tools, such as a patient decision aid, can be used to inform men on the clinical equipoise and guide them to make an informed decision about prostate cancer screening. ${ }^{45}$ Qualitative studies should be conducted to explore, understand and explain the factors that influence Malaysian GPs to screen for prostate cancer, particularly what influence their decision to perform PSA on themselves.

\section{CONCLUSION}

This study found that more than half of the GPs would screen and perform a PSA test despite lack of consensus on prostate cancer screening. They did not routinely involve men in making an informed decision about prostate cancer screening. In addition, we found that GPs' willingness to perform a PSA test on themselves significantly influenced their decision to perform PSA testing for their patients. This important finding highlights the need for future studies to explore how GPs' personal health beliefs and practice influence their clinical decision-making.

Acknowledgements The authors thank Associate Professor Dr Claire Choo Wan Yuen for providing expertise in analysis of the data. They also acknowledge all respondents for their participation in the study.

Contributors AMTF collected the data. AMTF and CJN participated in the analysis, data interpretation and preparation of the manuscript. All authors contributed to the design and conduct of the study. All authors read and approved the final manuscript.

Funding This work was supported by the University of Malaya postgraduate research fund (grant number: P0037/2013A).

Competing interests None declared.

Ethics approval This study was approved by the University Malaya Medical Centre Medical Ethics Committee (reference number: 968.6). Written informed consent was obtained from participants.

Provenance and peer review Not commissioned; externally peer reviewed.

Data sharing statement No additional data are available.

Open Access This is an Open Access article distributed in accordance with the Creative Commons Attribution Non Commercial (CC BY-NC 4.0) license, which permits others to distribute, remix, adapt, build upon this work noncommercially, and license their derivative works on different terms, provided the original work is properly cited and the use is non-commercial. See: http:// creativecommons.org/licenses/by-nc/4.0/

\section{REFERENCES}

1. Schroder FH, Hugosson J, Roobol MJ, et al. Screening and prostate-cancer mortality in a randomized European study. $N$ Engl J Med 2009;360:1320-8.

2. Schroder FH, Hugosson J, Roobol MJ, et al. Screening and prostate cancer mortality: results of the European Randomised Study of Screening for Prostate Cancer (ERSPC) at 13 years of follow-up. Lancet 2014;384:2027-35. 
3. Andriole GL, Crawford ED, Grubb RL III, et al. Mortality results from a randomized prostate-cancer screening trial. N Engl J Med 2009;360:1310-19.

4. Andriole GL, Crawford ED, Grubb RL III, et al. Prostate cancer screening in the randomized Prostate, Lung, Colorectal, and Ovarian Cancer Screening Trial: mortality results after 13 years of follow-up. J Natl Cancer Inst 2012;104:125-32.

5. Heidenrich A, Bastian PJ, Bellmunt J, et al. EUA Guidelines on Prostate Cancer. 2013. (4 September 2013). http://www.uroweb.org/ gls/pdf/09_Prostate_Cancer_LR.pdf

6. (NCCN) NCCN. Prostate Cancer Early Detection (Version 1.2014). 2014. (26 March 2014). http://www.nccn.org/professionals/physician gls/pdf/prostate_detection.pdf

7. Moyer VA. Screening for prostate cancer: U.S. Preventive Services Task Force recommendation statement. Ann Intern Med 2012;157:120-34.

8. Carter HB, Albertsen PC, Barry MJ, et al. Early detection of prostate cancer: AUA Guideline. J Urol 2013;190:419-26.

9. Qaseem A, Barry MJ, Denberg TD, et al. Screening for prostate cancer: a guidance statement from the Clinical Guidelines Committee of the American College of Physicians. Ann Intern Med 2013;158:761-9.

10. Wolf AMD, Wender RC, Etzioni RB, et al. American Cancer Society Guideline for the Early Detection of Prostate Cancer: Update 2010. CA Cancer J Clin 2010;60:70-98.

11. Thompson Intramuscular, Ankerst DP, Chi C, et al. Assessing prostate cancer risk: results from the Prostate Cancer Prevention Trial. J Natl Cancer Inst 2006;98:529-34.

12. Rosario DJ, Lane JA, Metcalfe $C$, et al. Short term outcomes of prostate biopsy in men tested for cancer by prostate specific antigen: prospective evaluation within ProtecT study. BMJ 2012;344: d7894.

13. Wilt TJ, MacDonald R, Rutks I, et al. Systematic review: comparative effectiveness and harms of treatments for clinically localized prostate cancer. Ann Intern Med 2008;148:435-48.

14. Durham J, Low M, McLeod D. Screening for prostate cancer: a survey of New Zealand general practitioners. N Z Med J 2003;116: U476.

15. Drummond F, Carsin AE, Sharp L, et al. Factors prompting PSA-testing of asymptomatic men in a country with no guidelines: a national survey of general practitioners. BMC Fam Pract 2009;10:3.

16. Curran V, Solberg S, Mathews M, et al. Prostate cancer screening attitudes and continuing education needs of primary care physicians. J Cancer Educ 2005;20:162-6.

17. Tasian GE, Cooperberg MR, Potter MB, et al. PSA screening: determinants of primary-care physician practice patterns. Prostate Cancer Prostatic Dis 2012;15:189-94.

18. Brett J, Watson E, Hewitson P, et al. PSA testing for prostate cancer: an online survey of the views and reported practice of General Practitioners in the UK. BMC Fam Pract 2005;6:24.

19. Gormley GJ, Catney D, McCall JR, et al. Prostate-specific antigen testing: uncovering primary care influences. BJU Int 2006;98:996-1000.

20. Melia J, Moss S, Johns L, Contributors in the participating laboratories. Rates of prostate-specific antigen testing in general practice in England and Wales in asymptomatic and symptomatic patients: a cross-sectional study. BJU Int 2004:94:51-6.

21. Burford DC, Kirby M, Austoker J. Prostate Cancer Risk Management Programme information for primary care; PSA testing in asymptomatic men. Evidence document: NHS Cancer Screening Programmes. 2010. (4 Nov 2013). http://www.cancerscreening.nhs. uk/prostatepcrmp-guide-2.html

22. Chen $\mathrm{YC}$, Page JH, Chen R, et al. Family history of prostate and breast cancer and the risk of prostate cancer in the PSA era. Prostate 2008;68:1582-91.

23. Breast Cancer Linkage Consortium. Cancer risks in BRCA2 mutation carriers. J Natl Cancer Inst 1999;91:1310-16.
24. Huncharek M, Haddock KS, Reid R, et al. Smoking as a risk factor for prostate cancer: a meta-analysis of 24 prospective cohort studies. Am J Public Health 2010;100:693-701.

25. Cogliano VJ, Baan R, Straif $\mathrm{K}$, et al. Preventable exposures associated with human cancers. J Natl Cancer Inst 2011;103:1827-39.

26. Crowe FL, Key TJ, Appleby PN, et al. Dietary fat intake and risk of prostate cancer in the European Prospective Investigation into Cancer and Nutrition. Am J Clin Nutr 2008;87:1405-13.

27. Buckley BS, Lapitan MC, Simpson CR, et al. Risk of prostate cancer associated with benign prostate disease: a primary care casecontrol study. Br J Gen Pract 2011;61:e684-91.

28. Zainal AO ZM, Nor Saleha IT. Malaysian Cancer Statistics: Data and Figure Peninsular Malaysia. In: Malaysia NCRMoH, editor. 2006.

29. Hoffman RM. Screening for prostate cancer. In UpToDate: UpToDate. 2014. (1 Sept 2012). http://uptodate.com/contents/ screening-for-prostate-cancer

30. Mistry K, Cable G. Meta-analysis of prostate-specific antigen and digital rectal examination as screening tests for prostate carcinoma. J Am Board Fam Pract 2003;16:95-101.

31. Hoogendam A, Buntinx F, de Vet HC. The diagnostic value of digital rectal examination in primary care screening for prostate cancer: a meta-analysis. Fam Pract 1999;16:621-6.

32. Gosselaar C, Roobol MJ, Roemeling S, et al. The role of the digital rectal examination in subsequent screening visits in the European randomized study of screening for prostate cancer (ERSPC), Rotterdam. Eur Urol 2008;54:581-8.

33. Kuppusamy S, Quek KF, Razack AH, et al. Assessment of Diagnostic performance of Prostate Specific Antigen (PSA) in a nation of low Prostate cancer incidence. BJU Int 2009;103(Suppl 1):22.

34. Hoag NA, Davidson RA, Pommerville PJ. Prostate cancer screening practices and attitudes among primary care physicians in Victoria, British Columbia. B C Med J 2008;50:456-60.

35. Francke A, Smit M, de Veer A, et al. Factors influencing the implementation of clinical guidelines for healthcare professionals: a systematic meta-review. BMC Med Inform Decis Mak 2008;8:38.

36. Ilic D, Murphy K, Green S. What do general practitioners think and do about prostate cancer screening in Australia? Aust Fam Physician 2013;42:904-8.

37. Tasian GE, Cooperberg MR, Cowan JE, et al. Prostate specific antigen screening for prostate cancer: knowledge of, attitudes towards, and utilization among primary care physicians. Urol Oncol 2012;30:155-60.

38. Star T. Check your prostate: prostate cancer screening is vital in the early detection of prostate diseases. The Star 2007.

39. $\mathrm{Ng}$ CJ, Lee PY, Lee YK, et al. An overview of patient involvement in healthcare decision-making: a situational analysis of the Malaysian context. BMC Health Serv Res 2013;13:408.

40. Davis K, Haisfield L, Dorfman C, et al. Physicians' attitudes about shared decision-making for prostate cancer screening. Fam Med 2011;43:260-6.

41. Haggerty J, Tudiver F, Brown JB, et al. Patients' anxiety and expectations: how they influence family physicians' decisions to order cancer screening tests. Can Fam Physician 2005;51:1658-9.

42. Gabbay J, le May A. Evidence based guidelines or collectively constructed "mindlines?" Ethnographic study of knowledge management in primary care. BMJ 2004;329:1013.

43. Johnson K, Chang M, Sun Y, et al. Attitudes and knowledge of primary care physicians regarding prostate cancer screening. $J$ Cancer Educ 2013;28:679-83.

44. Moran WP, Cohen SJ, Preisser JS, et al. Factors influencing use of the prostate-specific antigen screening test in primary care. $A m$ $J$ Manag Care 2000;6:315-24.

45. Flanigan TS, McFarlane E, Cook S. Conducting survey research among physicians and other medical professionals: a review of current literature. In: Proceedings of the American Statistical Association Survey Research Methods Section (AAPOR '08), New Orleans, LA USA. May 2008, pp 4136-47. 